\title{
AVALIAÇÃO DO PROCESSO PRODUTIVO DE UMA OLARIA COMO ALTERNATIVA PARA REDUÇÃO DE PERDAS COM PRODUTOS DISFORMES
}

\author{
Maria N. P. Araújo (1), Cybelle R. Duarte (1) e Ana C. de Almeida Prado (2) \\ (1) Universidade Federal de Pernambuco. Centro de Ciências Exatas e Da Natureza, Avenida Jornalista Aníbal Fernandes, s/no, \\ Cidade Universitária, CEP 50740-560, Recife - PE \\ (2) Universidade Federal do Cariri. Unidade Acadêmica Centro de Ciências e Tecnologia, Av. Tenente Raimundo Rocha S/N - \\ Bairro Cidade Universitária, CEP: 63048-080, Juazeiro do Norte - CE. \\ E-Mail: ana.prado@ufca.edu.br.
}

\begin{abstract}
RESUMO
O segmento oleiro-cerâmico desenvolve a economia brasileira consideravelmente, especificamente na região deste estudo o setor contribui fortemente para geração de emprego, renda, movimentação de dinheiro e abastecimento do comércio. Porém, as olarias, em sua maioria, possuem processo produtivo carente de tecnologia, organização e estrutura, gerando muitos produtos disformes e, consequentemente, perdas significativas. Assim, o presente trabalho objetiva diagnosticar as causas e quantificar os percentuais de produtos disformes gerados em uma olaria do município do Crato-CE e propor soluções para reduzir as perdas. Para tanto, realizou-se o acompanhamento das etapas do processo analisando por meio de cálculos a produção e as perdas geradas. No estudo, verificou-se que o percentual de perdas na etapa de queima foi maior comparado às etapas de conformação e secagem. Constatou-se que problemas mecânicos e secagem incompleta foram principais causas influenciadoras na geração de perdas. Por fim, foram propostas algumas medidas visando aumentar a produtividade das cerâmicas.
\end{abstract}

PALAVRAS - CHAVE: Cerâmica Vermelha. Processo produtivo. Peças disformes.

\section{Introdução}

O setor de cerâmica vermelha integra a produção de um conjunto de produtos tais como telhas, tijolos, blocos, lajes, lajotas, entre outros, cujo grande destaque de utilização se dá no setor da Construção Civil, principalmente como elemento estrutural, necessitando assim, de propriedades mecânicas essenciais à essa aplicação. Neste sentido, o ciclo de fabricação dos produtos de cerâmica vermelha requer métodos que agreguem qualidade, economia e bom desempenho na obtenção desses materiais.

O processo produtivo da indústria de cerâmica vermelha é simples e se constitui basicamente das etapas de extração, desintegração, mistura das argilas; após, a massa passa por laminação, extrusão, corte, secagem, queima; e, finalmente, inspeção, estocagem e expedição do produto. Em todas estas etapas, existe a possibilidade da ocorrência de diversos tipos de problemas que são responsáveis por afetar diretamente o produto final, diminuindo sua qualidade. Entre as principais falhas associadas aos materiais cerâmicos podem-se citar: trincas, deformações, variação no processo de extrusão, variação na amperagem, variação no corte, variação na regulagem da boquilha e variação na quantidade produzida (1).

Um dos grandes desafios desse setor cerâmico é a fabricação adequada dos produtos em detrimento das diversas variáveis presentes que devem ser analisadas criteriosamente. Muitas são as dificuldades encontradas pelo setor, tais como: existência de processos produtivos ultrapassados; defasagem tecnológica e obsolescência de maquinário; falta de conhecimento técnico para a preparação da argila; falha no processo de extrusão; falta de regulagem das boquilhas, entre outras (2).

Por se tratar de produtos com baixo valor agregado, o frete para o transporte tanto das matérias-primas, como do produto final é um fator determinante para a localização das indústrias. Sendo assim, estrategicamente as empresas do segmento oleiro-cerâmico se firmam em locais com disponibilidade da matéria-prima e acessibilidade aos principais consumidores. Em razão disto, muitas dessas empresas tem se instalado no munícipio de Crato, na Região Sul do estado do Ceará, devido tanto a existência de um solo rico em jazidas como também pelo crescente avanço da construção civil na região (3),(4). Segundo o SINDICERAMICA/CE, em documento fornecido em 2017, existem 36 empresas de produção de cerâmica na região e destas, 15 estão localizadas no Crato, sendo este o munícipio com maior número de empresas na região.

Diante deste contexto é inegável a importância do setor para economia local, gerando emprego e renda na região. Todavia, em razão das muitas dificuldades encontradas pelo segmento se faz necessário a investigação de todo o processo produtivo com a finalidade de identificar os principais problemas que atinge a produção e buscar melhorias com base nessa vertente. Assim, o objetivo geral desse trabalho foi quantificar e diagnosticar causas de peças/produtos disformes gerados no processo produtivo de uma olaria localizada no município do Crato-CE e 
propor soluções para reduzir as perdas. Para tanto teve os seguintes objetivos específicos: verificar a quantidade de perdas com peças disformes em diferentes etapas do processo produtivo; identificar qual é ou quais são a(s) etapa(s) do processo produtivo que mais estão influenciando na obtenção de peças que não apresentem uniformidade; averiguar as possíveis causas dos defeitos; sugerir possíveis mudanças que contribuam para o aperfeiçoamento do processo produtivo, minimizando a quantidade de perdas com esses materiais.

\section{Experimental}

Diante do objetivo proposto, o método utilizado na pesquisa foi o estudo de caso. O procedimento experimental foi o acompanhamento do processo produtivo de uma olaria na cidade de Crato, localizada na região do Cariri. A coleta de dados ocorreu no mês de março de 2018 e se deu por meio de observação direta do processo de produção, conversa com funcionários da empresa e análise documental. As atividades empregadas para o desenvolvimento do estudo estão descritas a seguir:

\section{Análise dos produtos disformes gerados}

A geração de produtos disformes foi avaliada para três etapas principais do processo de fabricação: conformação, secagem e queima. Esta análise foi feita durante um mês e calculou-se a produção e as perdas geradas em cada etapa. A ausência de controle na quantidade produzida em cada uma dessas etapas do processo, fez com que parte dos dados fossem obtidos de forma indireta, por meio de estimativas feitas pelos trabalhadores da fábrica que usaram de sua experiência para transformar a análise visual do volume em número de peças.

\section{- Análise dos produtos disformes gerados na etapa de conformação}

A olaria em estudo fabrica essencialmente blocos cerâmicos e se utiliza de vagonetas para armazenar seus materiais, bem como realizar o transporte deles na fábrica. Com base na verificação de que cada vagoneta comporta um total de 840 peças, de forma bastante simples foi possível obter os dados relativos à produção dessa etapa do processo: os trabalhadores responsáveis possuíam um caderno de anotações, neste caderno estava contido o total de vagonetas que saiam com peças conformadas diariamente, como cada vagoneta cabe 840 peças, por multiplicação simples foi possível calcular a quantidade da produção diária. No entanto, para o controle das perdas geradas, foi encontrada uma dificuldade, uma vez que não havia a prática desse controle na olaria. O descarte dos produtos era feito rapidamente em julietas (denominação dada ao carrinho em que era depositado o material disforme gerado) e não existia a contagem detalhada dessas peças. A contagem foi feita de modo estimado pelos trabalhadores, que devido a experiência sabiam a quantidade de peças que eram armazenadas em média nas julietas e transformavam a análise visual do volume disposto na julieta em número de peças.
É importante enfatizar que os dados coletados foram relativos aos dias da semana compreendidos de segunda a sábado, pois na empresa em questão a maromba não funciona aos domingos e, no sábado, funciona apenas meio período.

\section{- Análise dos produtos disformes gerados na etapa de secagem}

A etapa de secagem na olaria é feita de forma natural e artificial. Em ambos os tipos, não havia nenhum controle do que era produzido e dos produtos disformes gerados. Assim, devido á dificuldade de obtenção dos dados relativos à essa etapa (tanto pela existência de dois mecanismos de secagem - natural e artificial, como também pela limitação por parte dos trabalhadores para realizar o controle dos produtos que saiam com defeitos ou sem defeitos), a análise foi realizada de maneira aproximada considerando dados de três (3) dias intercalados durante a semana, não sendo possível obter o resultado específico do que era produzido e perdido diariamente. Portanto, os resultados estimados são de produção e perdas semanais.

$\mathrm{Na}$ empresa, havia a prática da contagem da quantidade de linhas que eram enfornadas e desenfornadas diariamente na cerâmica. Detalhadamente, essa avaliação se deu da seguinte forma: o forno contínuo, constituído de linhas, armazenava em cada linha 1760 peças, assim, pela quantidade de linhas enfornadas diariamente, sabia-se a quantidade de peças secas que foram enfornadas (consideradas sem defeitos). As quantidades diárias de tijolos enfornados (ou secos perfeitos) foram somadas para se obter o valor da produção na secagem semanal.

Para a análise das perdas geradas na secagem foi observada a quantidade de vagonetas que em média era enviada para a queima a cada semana e os produtos disformes que permaneciam nas vagonetas para serem encaminhados novamente ao processo. A quantidade de vagonetas que sai da secagem para o forno foi calculada pela divisão da quantidade de peças secas perfeitas calculadas na etapa anterior por 840 (que é o número de tijolos que cabe em uma vagoneta). As perdas obtidas nessa etapa foram, portanto, analisadas pela estimativa da quantidade aproximada de peças com defeitos que permaneciam nas vagonetas vezes o número de vagonetas.

\section{- Análise dos produtos disformes gerados na etapa de queima}

Para a etapa de queima, a olaria apresentava controle do que era produzido por meio da contagem da quantidade de linhas desenfornadas diariamente. Assim, a análise da quantidade de peças produzidas foi feita de modo simples por meio da multiplicação da quantidade de linhas que eram desenfornadas por dia vezes o número de peças que compõe uma linha (1760 tijolos).

Devido à empresa não ter controle dos produtos disformes gerados nesta etapa, a análise das perdas foi feita de forma aproximada, pelos trabalhadores responsáveis pelo setor de queima que conseguiam, pela prática do trabalho, transformar o volume de peças defeituosas descartadas em cada linha, em dado numérico. 
Aqui, diferente da etapa de conformação, os dados coletados foram relativos a todos os dias da semana (segunda a domingo), pois como o forno utilizado pela empresa é do tipo contínuo, ele permanece ligado e os trabalhadores realizam o processo de desenforma continuamente, funcionando essa etapa inclusive, aos domingos.

\section{Análise dos principais defeitos verificados nas peças}

Diversos tipos de defeitos comumente encontrados nas peças foram destacados e verificados nas etapas de conformação, secagem e queima. A análise dos defeitos foi realizada a partir da imagem de registros fotográficos retirados ao longo do estudo de caso.

\section{Correlação das possíveis causas com os defeitos}

Com base nas observações feitas diariamente na olaria, fez-se também, uma correlação com o percentual de defeitos observados a fim de identificar as possíveis razões que interferiram na geração de perdas.

Uma das hipóteses de causa para defeitos encontrados é a ocorrência de chuvas, isto porque em dias chuvosos, a umidade relativa do ar é mais alta, o que reduz a velocidade de secagem natural. O contrário vale para os dias ensolarados com baixa umidade relativa do ar. Diante disso, seguindo as informações da Fundação Cearense de Meteorologia e Recursos Hídricos - FUNCEME (2014) foi realizada uma análise dos índices de chuvas medidos durante o mês de março de 2018 com o objetivo de correlacionar os períodos chuvosos às perdas obtidas durante o processamento, principalmente na etapa de secagem. Como a FUNCEME não fornece os dados dos índices pluviométricos relativos à cidade de Crato, a pesquisa utilizou-se das informações referentes às cidades de Farias Brito e Barbalha, os postos mais próximos à cidade de Crato (Ceará).

\section{Proposição de soluções para reduzir as perdas}

A partir das observações realizadas e na análise das variáveis investigadas nesse estudo foram sugeridas algumas medidas para redução das perdas com produtos disformes.

\section{Resultados e Discussão}

\subsection{Análises da produção e perdas}

\subsubsection{Processo de conformação}

A Tabela I apresenta os dados de produção e perdas gerados durante a conformação com o resultado do cálculo de algumas medidas estatísticas, como a média e o desvio padrão.

$\mathrm{Na}$ avaliação das perdas, verificou-se que em média se descarta diariamente um total de $1,18 \%$ dos produtos fabricados devido a alguma deformidade na etapa da extrusão. Este valor é muito próximo do percentual total de perdas na produção durante o mês, indicando que a variação percentual de descarte no processo produtivo é muito pequena, como pode ser evidenciado através do cálculo do desvio padrão do percentual diário de perdas que retorna um valor de $0,005 \%$.

A partir de uma análise estatística dos dados obtidos, conclui-se que a variação diária do número de peças produzidas é alta (com uma média de 38.382 e um desvio padrão de 11.895 unidades).

\subsubsection{Processo de secagem}

Os dados de produção e perdas, semanal, no processo de secagem estão apresentados na Tabela II. A partir desta tabela é possível verificar que para esta etapa do processo, durante o período de observação, o percentual total de produtos disformes foi de aproximadamente 3,01\%.

Tabela I - Produção e perdas no processo de conformação.

\begin{tabular}{lcccc}
\hline & Produção & $\begin{array}{c}\text { Números de } \\
\text { peças com } \\
\text { defeitos }\end{array}$ & $\begin{array}{c}\text { Percentual } \\
\text { de peças com } \\
\text { defeitos }\end{array}$ & $\begin{array}{c}\text { Número de peças } \\
\text { sem defeitos }\end{array}$ \\
\hline Total do mês de março de 2018 & 997.920 & 11.885 & $1,19 \%$ & 986.035 \\
Média por dia & 38.382 & 475 & $1,18 \%$ & 37.924 \\
Desvio Padrão da média diária & 11.895 & 241 & $0,005 \%$ & 11.733 \\
\hline
\end{tabular}

Fonte: própria.

Tabela II - Produção e perdas no processo de secagem.

\begin{tabular}{|c|c|c|c|c|c|}
\hline Período & $\begin{array}{c}\text { Linhas } \\
\text { enfornadas }\end{array}$ & $\begin{array}{c}\text { Peças secas sem } \\
\text { defeitos }\end{array}$ & $\begin{array}{l}\text { Produção da } \\
\text { secagem total }\end{array}$ & $\begin{array}{c}\text { Peças secas com } \\
\text { defeitos }\end{array}$ & $\begin{array}{c}\text { Percentual } \\
\text { de peças com } \\
\text { defeitos após a } \\
\text { secagem }\end{array}$ \\
\hline $1^{\mathrm{a}}$ semana & 44 & 77.440 & 79.328 & 1.888 & $2,38 \%$ \\
\hline $2^{\mathrm{a}}$ semana & 150 & 264.000 & 272.081 & 8.081 & $2,97 \%$ \\
\hline $3^{\text {a }}$ semana & 136 & 239.360 & 251.323 & 11.963 & $4,76 \%$ \\
\hline $4^{\mathrm{a}}$ semana & 140 & 246.400 & 253.942 & 7.542 & $2,97 \%$ \\
\hline $5^{a}$ semana & 113 & 198.880 & 201.275 & 2.395 & $1,19 \%$ \\
\hline Total mensal & 583 & 1.026 .080 & 1.057 .949 & 31.869 & $3,01 \%$ \\
\hline Média semanal & 117 & 205.216 & 211.590 & 6.374 & $2,85 \%$ \\
\hline Desvio padrão semanal & 43 & 75.307 & 78.472 & 4.227 & $0,013 \%$ \\
\hline
\end{tabular}

Fonte: própria. 
Ainda de acordo com os dados apresentados na Tabela II por meio de análise estatística, verificou-se que em média nesta etapa são produzidas 211.590 peças por semana e o valor do desvio padrão foi de 78.472, portanto a etapa de secagem apresenta alta variação na sua produtividade semanal. Na análise das perdas, observou-se que o percentual de perdas em média foi de $2,85 \%$ por semana, valor que apresenta uma proximidade do percentual total de perdas na produção, indicando que a variação percentual de descarte semanal é pequena, como pode ser evidenciado pelo desvio padrão calculado: $0,013 \%$.

\subsubsection{Processo de queima}

A Tabela III apresenta os dados de produção e perdas referentes a etapa de queima. Verificou-se que em média se produz 34.803 peças diariamente e o valor do desvio padrão foi de 15.805 , indicando que existe uma variação significativa da produção de um dia para outro. Na análise das perdas, observou-se que o percentual de perdas em média foi de $9,25 \%$ por semana e o desvio padrão foi de 0,033\%, como pode ser observado na Tabela III, houve variação no percentual de perdas de um dia para o outro durante a queima.

A Figura 1 apresenta, graficamente, o total percentual de produção e perdas relativas às três etapas do processo que foram analisadas.

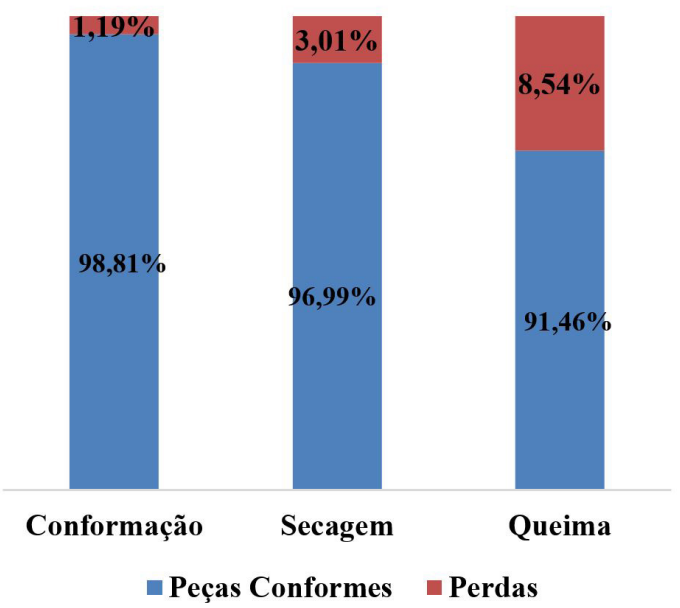

Figura 1 - Percentual de peças consideradas conformes e disformes (perdas) nas etapas de conformação, secagem e queima do processo da olaria. Fonte: própria.

\subsection{Análise dos principais defeitos verificados nas peças}

\subsubsection{Processo de conformação}

Na Figura 2, podem ser observados alguns dos defeitos que foram verificados nos produtos da olaria. Dentre estes defeitos pode-se observar peças que apresentaram diretamente o rompimento da parede interna e deformações e cortes que podem ter sido causados por impurezas que foram observadas na massa (atuando como concentradores de tensão) e/ou uma plasticidade não ideal e/ou de problemas mecânicos.

\subsubsection{Processo de secagem}

A Figura 3 apresenta fotografias de defeitos que foram comumente verificados para o processo de secagem. Onde pode ser visto que os defeitos mais encontrados são fissuras, trincas e fraturas. Apresentando com maior incidência, as trincas, que podem ter sido causadas justamente por (a)

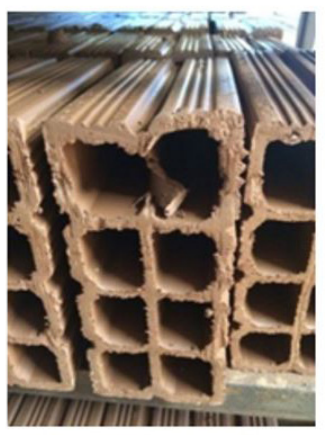

(c)

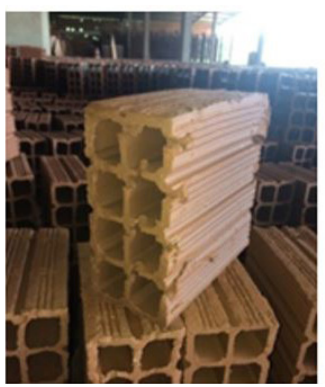

(b)

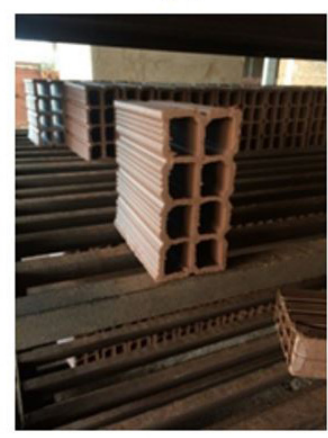

(d)

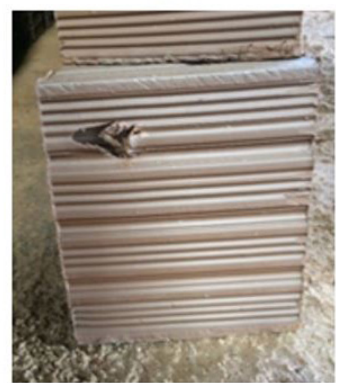

Figura 2 - Defeitos na etapa de conformação. a) rompimento da parede interna do tijolo; b) faces não planas; c) deformações e cortes; d) furo. Fonte: própria

Tabela III - Produção e perdas no processo de queima

\begin{tabular}{lcccc}
\hline & Produção & $\begin{array}{c}\text { Números de } \\
\text { peças com } \\
\text { defeitos }\end{array}$ & $\begin{array}{c}\text { Percentual } \\
\text { de peças com } \\
\text { defeitos }\end{array}$ & $\begin{array}{c}\text { Número de peças } \\
\text { sem defeitos }\end{array}$ \\
\hline Total do mês de março de 2018 & 1.078 .880 & 92.165 & $8,54 \%$ & 986.715 \\
Média por dia & 34.803 & 2.973 & $9,25 \%$ & 31.830 \\
Desvio Padrão da média diária & 15.805 & 1.054 & $0,033 \%$ & 15.253 \\
\hline
\end{tabular}

Fonte: própria. 
essa ausência de controle na velocidade de secagem, pois como maior parte do processo de secagem é feito de forma natural, há a existência de oscilações de tempo chuvoso e seco, ventos e outras interferências externas que não permitem que a velocidade de secagem natural seja controlada.

\subsubsection{Processo de queima}

Na Figura 4, estão expostos os defeitos mais comumente observados na queima. Conforme pode ser visto nas imagens além de coloração diferenciada estão presentes também muitas fraturas e trincas. Tais defeitos (a)

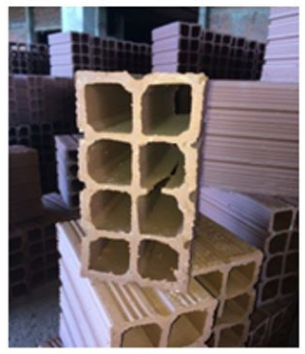

(d)

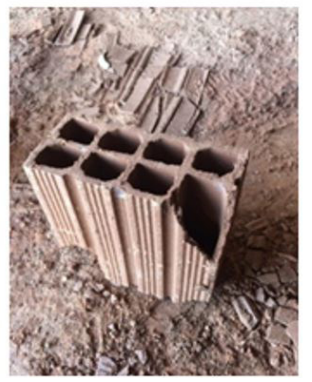

(b)

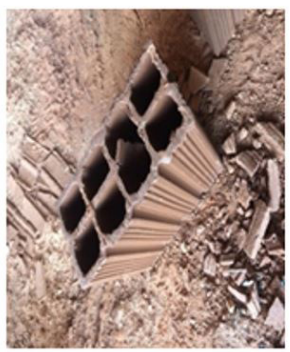

(e)

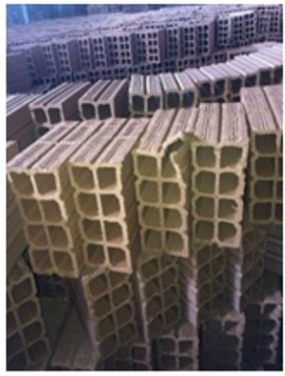

(c)

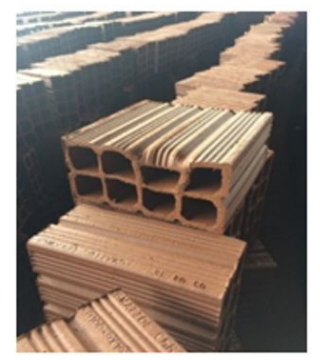

(f)

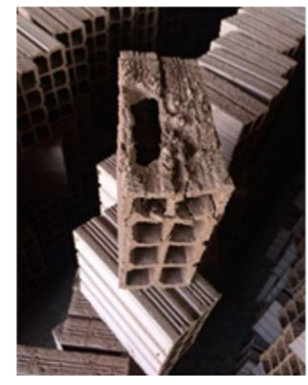

Figura 3 - Defeitos na etapa de secagem. a) trinca; b) rompimento da parede interna do tijolo; c e e) deformações; d) bloco fraturado; f) furo. Fonte: própria.

(a)

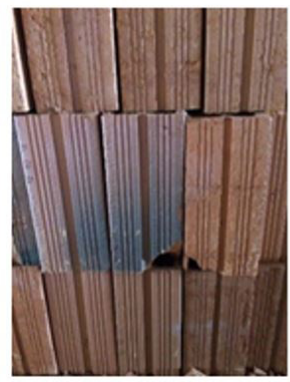

(e)

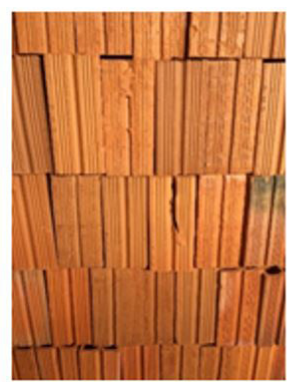

(b)

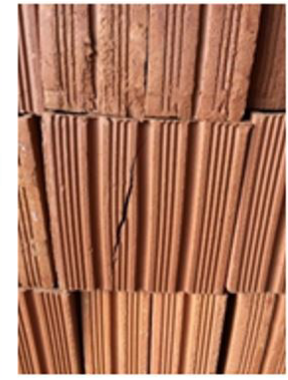

(f)

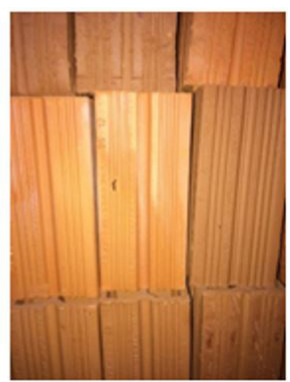

(c)

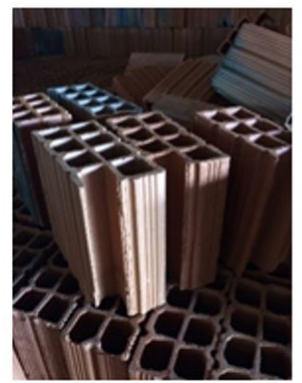

(g)

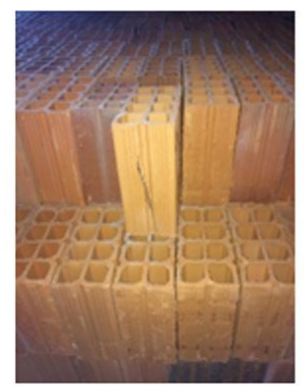

(d)

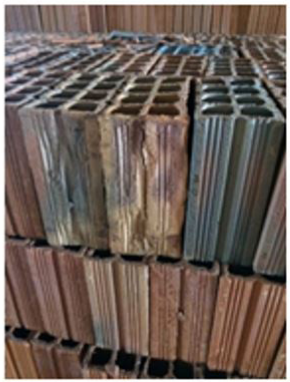

(h)

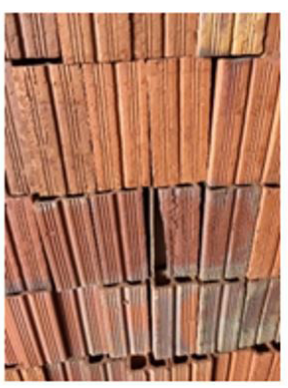

Figura 4 - Defeitos na etapa de queima. a e e) fraturas e diferenças na coloração (coloração escura); b e g) trincas; c e h)fratura; d) trinca e irregularidade na superfície; f) furo. Fonte: própria. 
são oriundos de vários fatores, como: tempo inadequado de permanência das peças no forno, temperatura irregular de queima, o combustível utilizado, peças com defeitos sendo submetidas a queima, secagem incompleta, entre outros.

\subsection{Possíveis causas dos defeitos}

Visando determinar as possíveis causas para os defeitos visualizados nos produtos e delinear a provável razão da geração de um maior percentual de defeitos de um determinado dia em relação ao outro, durante a realização desta pesquisa algumas observações foram anotadas nos dias em que foi realizado o monitoramento das atividades e a análise de produção e perdas. No Quadro I, são apresentadas, sucintamente, as principais observações feitas. Além destas observações, com o propósito de correlacionar os períodos chuvosos às perdas obtidas durante o processamento, foram analisados os índices pluviométricos do mês de março de 2018 obtidos por meio de informações da FUNCEME (2014), estes dados estão apresentados na Tabela IV.

Conforme as observações realizadas no Quadro I, na primeira semana de março (01/03/18 e 02/03/18), grande parte dos defeitos verificados na queima possivelmente foram oriundos do tempo demasiado de permanência das peças cerâmicas no forno, gerando coloração mais escura e deformações. Além disso, o problema mecânico apresentado no secador, atrasou a produção e muitas peças foram encaminhadas para a queima com secagem incompleta, gerando um maior percentual de defeitos na queima nos dias posteriores.

Quadro I - Principais observações realizadas na olaria.

\begin{tabular}{|c|c|c|c|c|}
\hline \multicolumn{5}{|c|}{ Observações realizadas } \\
\hline $01 / 03 / 18$ & \multicolumn{2}{|c|}{$\begin{array}{l}\text { Tempo demasiado dos blocos no forno, apresentando } \\
\text { colocações diferenciais, trincas e fissuras. }\end{array}$} & \multicolumn{2}{|c|}{$\begin{array}{l}\text { Problema mecânico no secador e por esse motivo } \\
\text { a maromba não foi ligada no período da manhã, o } \\
\text { que atrasou a fabricação dos blocos. }\end{array}$} \\
\hline $02 / 03 / 18$ & \multicolumn{2}{|c|}{$\begin{array}{l}\text { A lenha verde promove uma queima lenta e a lenha } \\
\text { seca promove uma queima mais rápida. }\end{array}$} & \multicolumn{2}{|c|}{$\begin{array}{l}\text { O sazonamento está sendo feito de forma adequada, } \\
\text { esse contribui de forma efetiva para uma série de } \\
\text { ações, como: decomposição de partículas orgânicas, } \\
\text { lixiviação dos sais minerais e homogeneização da } \\
\text { umidade melhorando as características da massa } \\
\text { durante o processamento }\end{array}$} \\
\hline $06 / 03 / 18$ & $\begin{array}{l}\text { Alguns blocos vão para forno sem } \\
\text { proceder a secagem completa, } \\
\text { saindo defeituosos. }\end{array}$ & \multicolumn{2}{|c|}{$\begin{array}{l}\text { As peças com defeitos na secagem } \\
\text { retornam ao processo. Enquanto } \\
\text { na queima, as peças com defeitos } \\
\text { são descartadas. }\end{array}$} & $\begin{array}{l}\text { Alguns trabalhadores manuseiam o } \\
\text { bloco jogando bruscamente durante } \\
\text { a expedição, quebrando-o. }\end{array}$ \\
\hline 08/03/18 & \multicolumn{4}{|c|}{$\begin{array}{l}\text { Problema no equipamento de corte da maromba, produzindo grande quantidade de perdas no processo } \\
\text { de conformação com a obtenção de materiais com defeitos. }\end{array}$} \\
\hline $09 / 03 / 18$ & $\begin{array}{l}\text { Após a mistura, na etapa de } \\
\text { preparação observa-se a presença } \\
\text { de galhos e impurezas. }\end{array}$ & \multicolumn{2}{|c|}{$\begin{array}{l}\text { Na esteira da maromba, antes de } \\
\text { passar no laminador e após passar } \\
\text { no misturador, observa-se também } \\
\text { a presença de galhos e sujeiras. }\end{array}$} & \\
\hline $13 / 03 / 18$ & \multicolumn{2}{|c|}{$\begin{array}{l}\text { Após um (1) ano, foi realizado a troca da boquilha da } \\
\text { maromba. As peças saíram com a espessura mais fina. }\end{array}$} & \multicolumn{2}{|c|}{$\begin{array}{l}\text { Reforma do caixão alimentador da maromba } \\
\text { Como consequência, foram produzidas peças com } \\
\text { defeitos, pois as sujeiras da construção afetaram a } \\
\text { massa argilosa. }\end{array}$} \\
\hline $15 / 03 / 18$ & \multicolumn{4}{|c|}{$\begin{array}{l}\text { Pequenas deformações apresentadas nas peças conformadas, provenientes dos rolos presentes no } \\
\text { equipamento que recebe a peça recém-moldada: mesa agrupadora. }\end{array}$} \\
\hline $16 / 03 / 18$ & \multicolumn{4}{|c|}{$\begin{array}{l}\text { Algumas deformações presentes nas peças durante a secagem natural são provenientes do brusco } \\
\text { manuseio do operador. }\end{array}$} \\
\hline $20 / 03 / 18$ & \multicolumn{2}{|c|}{$\begin{array}{l}\text { Na secagem artificial, existia apenas } 1 \text { (um) secador. } \\
\text { A capacidade do secador artificial era menor que } \\
\text { a quantidade de peças conformadas, o que gerava } \\
\text { lentidão no processo, pois muitas vagonetas ficavam } \\
\text { ocupadas com os blocos e não havia espaço no secador. }\end{array}$} & \multicolumn{2}{|c|}{$\begin{array}{l}\text { A secagem natural que é mais lenta que a artificial } \\
\text { estava demorando ainda mais, pois estava chovendo, } \\
\text { o que aumentou a umidade relativa do ar e diminuiu } \\
\text { a velocidade de secagem natural. }\end{array}$} \\
\hline $22 / 03 / 18$ & \multicolumn{4}{|c|}{ Bastante incidência de chuvas, retardando o processo de secagem, consequentemente a produção. } \\
\hline $23 / 03 / 18$ & \multicolumn{4}{|c|}{ Bastante incidência de chuvas, retardando o processo produtivo/ secagem incompleta das peças. } \\
\hline $27 / 03 / 18$ & \multicolumn{2}{|c|}{$\begin{array}{l}\text { Peças com secagem incompleta sendo encaminhadas } \\
\text { à queima. }\end{array}$} & \multicolumn{2}{|c|}{$\begin{array}{l}\text { Na secagem, observaram-se alguns materiais trincados } \\
\text { devido ao corte vindo da boquilha da maromba. }\end{array}$} \\
\hline 28/03/18 & \multicolumn{4}{|c|}{$\begin{array}{l}\text { Verificação de raízes presentes na massa, muitas vezes essas raízes ficam presas na boquilha da maromba, } \\
\text { tendo que fazer um corte na peça para retirar esse material da boquilha. }\end{array}$} \\
\hline
\end{tabular}

Fonte: própria. 
Tabela IV - Índices pluviométricos das cidades de Farias Brito e Barbalha em março de 2018.

\begin{tabular}{ccc}
\hline \multirow{2}{*}{ Período } & \multicolumn{2}{c}{ Cidade } \\
\cline { 2 - 3 } & Farias Brito & Barbalha \\
\hline $1^{\text {a }}$ Semana & $22.87 \mathrm{~mm}$ & $13.83 \mathrm{~mm}$ \\
$2^{\text {a }}$ Semana & $0.0 \mathrm{~mm}$ & $1.0 \mathrm{~mm}$ \\
$3^{\text {a }}$ Semana & $0.71 \mathrm{~mm}$ & $0.0 \mathrm{~mm}$ \\
$4^{\text {a }}$ Semana & $2.57 \mathrm{~mm}$ & $11.71 \mathrm{~mm}$ \\
\hline $5^{\text {a }}$ Semana & $4.71 \mathrm{~mm}$ & $8.07 \mathrm{~mm}$ \\
\hline
\end{tabular}

Fonte: dados compilados de FUNCEME (2014).

Similarmente, na segunda semana (06/03/18 à 09/03/18), sucederam muitas peças sendo encaminhadas para queima com secagem incompleta, na qual provavelmente foi a causa de grande parte dos defeitos obtidos na queima nos dias posteriores. Pois, as peças cerâmicas que contém umidade no seu interior estão sujeitas a formação de fendas ou trincas, geradas pelos gradientes térmicos (variação de temperatura) entre o centro e a superfície da peça. É válido atentar, ainda, ao problema no equipamento de corte da extrusora o que foi motivo de geração de defeitos na conformação.

É possível constatar de modo evidente, na Figura 5, que as etapas de conformação e secagem apresentaram um maior percentual de perdas durante a $3^{\mathrm{a}}$ semana, na qual pode ser observado no Quadro I, que na $3^{\mathrm{a}}$ semana $(13 / 03 / 18$ à 16/03/18) ocorreu exatamente a troca da boquilha da extrusora e a reforma do caixão alimentador da etapa de conformação. Por consequência, um maior percentual de defeitos na queima durante a $4^{\mathrm{a}}$ semana foi gerado, essa ocorrência pode ser explicada pelo fato da nova boquilha ter produzido peças com espessura mais fina, apresentando possivelmente menor resistência durante a queima.

Como observado no Quadro I, alguns defeitos que saem no produto durante a conformação são oriundos de raízes presentes na massa, muitas vezes essas raízes ficam presas na boquilha da extrusora, tendo que fazer um corte na peça para retirar esse material da boquilha.

Ainda mais, em análise a Tabela IV, relativa aos índices pluviométricos da cidade de Farias Brito e Barbalha, pode ser visto que na quarta e quinta semana do mês de março, ambas as cidades apresentaram incidência de chuvas, em paralelo a esse fato, no Quadro I, na $4^{\mathrm{a}}$ e $5^{\mathrm{a}}$ semana, foram observadas muitas peças sendo encaminhas ao forno com secagem incompleta, o que explica o elevado percentual de defeitos na queima durante essas semanas.

\subsection{Principais medidas para minimizar as perdas com produtos disformes}

Baseado nas observações realizadas e na análise das variáveis investigadas nesse estudo, as seguintes medidas são sugeridas como possíveis soluções para melhorar ainda mais a qualidade e a uniformidade dos produtos:

- Quantificação da capacidade de produção e percentual de defeitos em cada etapa do processo e

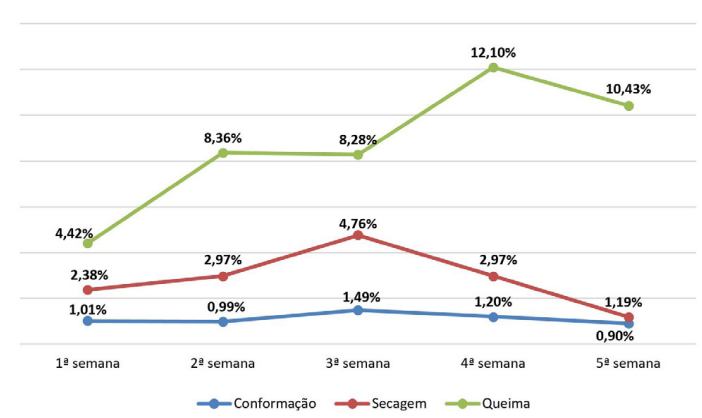

Figura 5- Percentual de defeitos semanais em cada etapa Fonte: própria.

planejamento da produção diária ou semanal com base na etapa que apresente menor capacidade produtiva;

- Controle da qualidade da massa argilosa por meio de testes de plasticidade, distribuição granulométrica e de umidade. Normalmente, a fábrica por experiência (tentativa, acerto e erro) define qual é proporção ideal entre a argila gorda, magra e água para a mistura e mantém essa proporção por longos períodos de tempo. Porém, a argila é um material natural que, à medida que é minerada, pode sofrer alteração de sua composição e, consequentemente, da sua plasticidade e da necessidade de água para sofrer a deformação adequada. Assim, recomendamos a coleta periódica e a realização desses testes em amostras da massa no misturador, antes da extrusão. Posteriormente, com tabelas e gráficos, as correlações de granulometria, umidade e plasticidade da massa com os percentuais de defeitos que ocorreram na extrusão e em todo o processo fabril devem ser realizadas. Assim, será possível determinar faixa de valores ideais de granulometria, de umidade e de plasticidade que geram menor percentual de defeitos. Após essa determinação de faixa de valores ideais, quando se coletar uma amostra de massa e verificar que a mesma apresenta uma característica fora da faixa de valores, é possível fazer ajustes a massa;

- Retirada de impurezas na massa mais eficiente, pois além de promover o alívio de tensões no produto retira o inconveniente provocado principalmente na etapa de conformação;

- Proceder de forma completa a secagem das peças para enviá-las à queima, o uso do secador artificial proporciona maior controle no tempo e nas condições de secagem, portanto sugerimos a instalação de secadores artificiais usando o calor que é desprendido dos fornos como fonte energética. Quando usar a secagem natural, recomendamos a proteção dos produtos da ação direta das chuvas, usando, por exemplo, lonas e realizar testes para verificar a umidade das peças; 
- Verificar a resistência mecânica dos produtos, pois como se sabe a aplicação fundamental desses materiais é como elemento estrutural, devendo resistir as diversas solicitações mecânicas durante o uso, sendo, portanto, extremamente importante verificar após as reações físico-químicas da queima se o material adquiriu a resistência necessária à sua aplicação;

- Verificar a absorção de água dos produtos, de modo a avaliar se os valores de absorção não comprometem a qualidade final do produto;

- Utilizar o critério de classificação de defeitos com base na ABNT NBR 15270-1 (2005) que estabelece os parâmetros que servem como base para identificar defeitos/imperfeições que não devem ser aceitos, já que na fábrica são os próprios operários que determinam as peças que devem ser descartadas ou não (sem a utilização de nenhum critério específico);

- Outros procedimentos (tempo de sazonamento; retirada de raízes, galhos ou outras impurezas que ainda ficam incrustadas na massa).

\section{Conclusões}

A realização desse estudo de caso permitiu conhecer de perto a realidade de uma olaria, verificando na prática as ações executadas e aquelas que necessitam ainda ser executadas. Como foi abordado, necessitou-se da elaboração de uma metodologia que pudesse permitir a quantificação mais aproximada dos dados relativos à produção e às perdas, pois na olaria em estudo, não havia esse quantitativo.

Portanto, o primeiro objetivo específico de verificar a quantidade de perdas com peças disformes em diferentes etapas do processo produtivo foi realizado e a etapa de queima apresentou um maior percentual de perdas em relação às etapas de conformação e secagem, vale ressaltar que essas perdas para cerâmica são mais relevantes, pois as peças disformes geradas após a sinterização não retornam ao processo produtivo.

Foi identificado tanto na etapa de preparação, como na conformação a presença de impurezas na massa argilosa que foram possíveis causas de defeitos. Além do mais, pode ser visto que a ausência da secagem completa das peças gerou um maior percentual de defeitos na etapa de queima, comprovando assim que as etapas do processo produtivo que mais influenciaram na obtenção de peças disformes foram as etapas de preparação da massa, conformação e secagem.

Durante a verificação das possíveis causas dos defeitos, foi visto que além da interferência das etapas do processo, existiram outras causas para a incidência de defeitos associadas que estavam diretamente ligadas aos aspectos mecânicos: problema no secador artificial, troca da boquilha, falta de regulagem das hélices dos misturadores.

Outra causa verificada foi o aumento no teor de chuvas, que influenciou na geração de uma maior parcela de defeitos na queima, mostrando que, os principais defeitos desta etapa foram oriundos da umidade ainda presentes nas peças que foram enviadas ao forno.

Algumas medidas puderam ser sugeridas visando contribuir com o aperfeiçoamento do processo produtivo, tais como: dosagem correta da mistura argilosa, melhorar as conexões entre as etapas, proceder a secagem de forma completa e testes de qualidade do produto final.

Enfim, conclui-se que foi possível realizar toda a quantificação e o diagnóstico das causas de peças/produtos disformes gerados no processo produtivo para uma olaria localizada no município do Crato-CE, que podem ser replicadas em qualquer fábrica cerâmica, propiciando contribuições diretas para as olarias com a proposição de medidas que visam aprimorar o processamento e as técnicas já empregadas.

\section{Referências}

[1] OLIVEIRA, A. A. Tecnologia em Cerâmica. Criciúma: Editora Lara, 2011.

[2] MACIEL, D. S. C.; FREITAS L. S. Análise do processo produtivo de uma empresa do segmento de cerâmica vermelha à luz da produção mais limpa. Revista produção online, Florianópolis, v.13, n.4, p. 1355-1380, out./ dez. 2013.

[3] XAVIER, A. S; SABIA, R. J.; DE FREITAS, F. R. D.; ARAUJO, M. S. G.; MARINHO, R. M. M. Experiência sustentável: desenvolvimento de mecanismo limpo adotado por uma indústria de cerâmica estrutural em Crato/ce. In: Encontro Nacional de Engenharia de Produção, XXXVI, 2016, João Pessoa, Anais... João Pessoa: ENEGEP, 2016. p. 1-12.

[4] GOMES, S. Construção Civil é o setor que mais emprega no Cariri. Folha Cearense, Fortaleza, 18 de fevereiro de 2019. Disponível em: <https://www.folhacearense.com.br/ destaque/2019/construcao-civil-e-o-setor-que-mais-empregano-cariri/>. Acesso em: 30 mar. 2019. 